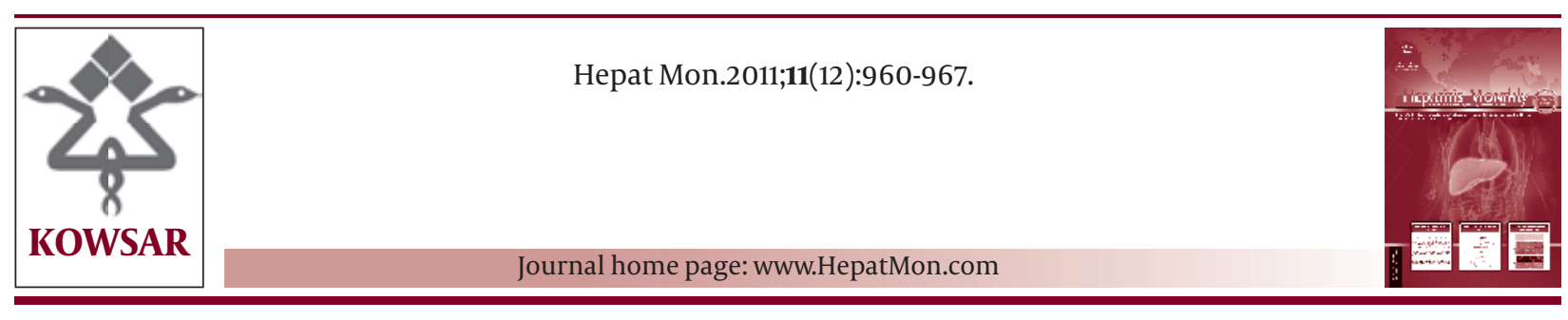

\title{
Clinical Features and Seroepidemiology of Anti-HDV Antibody in Pa- tients With Chronic Hepatitis B Virus Infection in Iran: A Meta-Analysis
}

\author{
Neda Amini ${ }^{1}$, Seyed Moayed Alavian ${ }^{2 *}$, Ali Kabir ${ }^{3,4}$, Seyed Yaser Saiedi Hosseini ${ }^{2}$, Seyed \\ Hossein Aalaei-Andabili ${ }^{2}$ \\ ${ }^{1}$ Tehran University of Medical Sciences, Students' Scientific Research Center, Tehran, IR Iran \\ ${ }^{2}$ Baqiyatallah Research Center for Gastroenterology and Liver Diseases, Baqiyatallah University of Medical Sciences, Tehran, IR Iran \\ ${ }^{3}$ Tehran University of Medical Sciences, Center for Educational Research in Medical Sciences, Tehran, IR Iran \\ ${ }^{4}$ Department of Epidemiology; Shahid Beheshti University of Medical Sciences, Tehran, IR Iran
}

\begin{tabular}{|c|c|}
\hline A R T I C L E I N F O & A B S T R A C T \\
\hline Article type: & Context: Hepatitis delta virus (HDV) leads to the most severe form of chronic viral hepatitis. \\
\hline Meta-Analysis & $\begin{array}{l}\text { Objectives: To determine the prevalence of HDV and create pooled estimations of possible } \\
\text { risk factors, a systematic review was conducted to collect all epidemiological studies on }\end{array}$ \\
\hline Article history: & HDV among chronic hepatitis B patients in Iran. \\
\hline Received: 15 Oct 2011 & Data Sources: In this systematic review, databases such as PubMed, Embase, ISI, Google \\
\hline Revise: 07 Dec 2011 & scholar, and Iranian databases (MagIran, Iranmedex, and SID) were searched. \\
\hline Accepted: 29 Dec 2011 & $\begin{array}{l}\text { Study Selection: Studies that clearly stated information about the number of HBsAg positive } \\
\text { patients infected with HDV were selected. }\end{array}$ \\
\hline Keywords: & Data Extraction: The name of the city, the author's name, year of study, HDV detection meth- \\
\hline Hepatitis D & od, sample size, HBsAg positive frequency, mean age, total prevalence of HDV, and risk fac- \\
\hline Review & tors were extracted. \\
\hline Meta-Analysis & Results: The pooled HDV prevalence was 7.8\% (95\% CI: 5.89 - 9.71). In the survey-data analysis, \\
\hline Iran & HDV prevalence was 6.61\%. HDV prevalence was 30.47\% (95\% CI: 9.76 to 51.19), $14.4 \%$ (95\% CI: \\
\hline Prevalence & 7.72 to 21.07 ), and $4.94 \%$ (95\% CI: 3.73 to 6.15 ) in cirrhotic, chronic-hepatitis, and inactive- \\
\hline Epidemiology & $\begin{array}{l}\text { carrier patients, respectively. Pooled ORs were calculated for several factors common to Ira- } \\
\text { nian HBsAg-positive patients, including history of blood transfusion [OR: } 1.1 \text { ( } 95 \% \text { CI: } 0.40 \\
\text { to } 2.98) \text { ], intravenous drug abuse [OR: } 1.6 \text { ( } 95 \% \text { CI: } 0.78 \text { to } 3.21)] \text {, previous hemodialysis [OR: } \\
1.72(95 \% \text { CI: 0.79 to 3.76)], and HBeAg-positive status [OR: } 1.26 \text { (95\% CI: } 0.66 \text { to 2.4)]. } \\
\text { Conclusions: The prevalence of HDV is less common in Iran than in endemic regions such } \\
\text { as Italy and Turkey; however, it is a severe form of hepatitis in HBsAg-positive patients. The } \\
\text { most probable route of HDV transmission is hematologic, which suggests the importance } \\
\text { of blood screening for HDV, especially in groups with numerous blood transfusions. }\end{array}$ \\
\hline
\end{tabular}

Copyright \& 2011 Kowsar M. P. Co. All rights reserved.

\begin{abstract}
Implication for health policy/practice/research/medical education:
This article is a collection of epidemiological studies on HDV in chronic hepatitis B patients in Iran. Study of the present article is highly recommended to hepatologists, gastroenterologists, virologists and epidemiologists.
\end{abstract}

\footnotetext{
Please cite this paper as:

Amini N, Alavian SM, Kabir A, Saiedi Hosseini SY, Aalaei-Andabili SH. Clinical Features and Seroepidemiology of Anti-HDV Antibody in Patients With Chronic Hepatitis B Virus Infection in Iran:A Meta-Analysis. Hepat Mon. 2011;11(12): 960-7.
}

\footnotetext{
* Corresponding author: Seyed Moayed Alavian, Baqiyatallah Research Center for Gastroenterology and Liver Diseases, Baqiyatallah University of Medical Sciences, Mollasadra St.,Vanak Sq., Tehran, IR Iran. Tel: +982188067114, Fax:+98-2188067114, E-mail: alavian@thc.ir

Copyright g2011 Kowsar M.P.Co. All rights reserved.
}

\section{Context}

Delta hepatitis infection leads to the most threatening form of chronic viral hepatitis, which can cause cirrhosis, fibrosis, and hepatocellular carcinoma (HCC) (1-3). Moreover, response to therapy is different and less satisfactory in patients with hepatitis delta virus (HDV) infection 
than hepatitis B virus (HBV) monoinfection (4). It is estimated that 15 to 20 million HBV patients are positive for anti-HDV antibody (5). The HDV incidence has declined in endemic countries in Western Europe such as Italy (6). Hence, HDV persists as an applicable cause of morbidity in Eastern Europe and the Mediterranean basin $(7,8)$. In Iran, as a country located in the Mediterranean basin, the prevalence of HBsAg carrier is $2.14 \%$, according to a recent review (9). Different rates of HDV infection among HBsAg-positive patients have been reported from Iran. The first report on this issue was described by Malekzadeh et $a l$. in asymptomatic hepatitis B carriers in Shiraz (South of Iran), in which HDV prevalence was 13.9\% (10), but recent studies have shown that HDV rates varied from $0 \%$ in northern Iran (11) to 20\% in southern Iran (12).

\section{Objectives}

To provide a clear estimate of HDV prevalence in Iran and address a gap in the field's knowledge, we designed a systematic review to collect all respective epidemiological studies conducted in Iran about HDV in chronic hepatitis B patients. The prevalence of HDV was analyzed separately in the setting of chronic hepatitis, liver cirrhosis, HCC, and inactive carriers to show the effects of HDV on hepatitis progression. We investigated regional differences as well as potential chronological changes to analyze epidemiological changes of hepatitis D in various parts of Iran. Pooled estimations for each possible risk factor, especially in high-risk groups, were calculated to identify the most important routes of HDV transmission.

\section{Data Sources}

The authors reviewed studies and evaluated the prevalence of HDV infection in HBsAg positive cases. The outcomes considered in this review were the prevalence and risk factors of HDV infection.

One author (N.A.) conducted an electronic literature search through Scopus, ISI, Google scholar, and three Medline database engines-PubMed, Embase, and Ovidusing different combinations of the word Iran and the key words "hepatitis D, Delta antigen, HDV, and hepatitis delta virus”. Iranian databases, including MagIran, IranMedex, and SID, were also searched with relevant English and Persian key words. At the time when these searches were conducted, the databases were limited to published and unpublished information up to and including December 2010. Search sensitivity was checked by considering duplicated papers. If the full text of articles were not accessible, an e-mail was sent to the author. If no response was received after one month, the abstract was used to extract data (except for articles with no informative abstracts, which were omitted).

\section{Study Selections}

Only studies that clearly stated information about the numbers of HBsAg-positive patients infected with HDV were selected. Studies in which all patients had acute hepatitis B (13-15) were excluded because the pattern of HDV is different in chronic and acute hepatitis. Investigators also excluded articles that were about the genotypes of HDV. The names of the authors and journals did not impact exclusion.

\subsection{Assessment of Study Quality}

A critical appraisal (CA) was conducted using the Epible checklist (16) by three investigators (NA, SH SY, and AA $\mathrm{SH}$ ) to evaluate the adequacy of sample size, research design, data collection, and presentation of results. If the investigators' scores were not close, they did conduct another CA together again. Based on the total CA score, articles were divided into low $(<40 \%)$, moderate (40 to $70 \%$ ), and high (>70\%) quality. Low-quality papers were not included in the main analysis but were included in subgroup analyses.

\section{Data Extraction}

Data extraction was completed by three investigators (NA, SH SY, and AA SH) and rechecked by one of them (NA). Information was entered into Microsoft Office Excel 2007. The name of the city the author's name, year of study, HDV-detection method, sample size, HBsAg-positive frequency, mean age, and total prevalence of HDV were extracted. Moreover, standard errors (SE) were calculated as $\mathrm{SE}=\sqrt{ }(\mathrm{P} \times[1-\mathrm{P}] / \mathrm{N})$, where $\mathrm{P}=$ prevalence and $\mathrm{N}=$ sample size. HDV prevalence was extracted in different subgroups consisting of cirrhotic patients, inactive carriers, chronic hepatitis patients, and male and female participants.

\subsection{Statistical Analysis}

A 95\% CI of the seroprevalence of anti-HDV antibody was computed for each of the included studies using the approximate normal distribution model. The summary estimate of HDV prevalence was calculated as an average of the individual study results weighted by the inverse of their variances using fix/random models (DerSimonian and Laird) based on the heterogeneity test result using Q, I-squared and Tau-squared statistics. Due to the low power of this test, a minimum cut-off $P$ value of 0.1 was established as a threshold of heterogeneity. Isquared lies between $0 \%$ and $100 \%$ and heterogeneity increases with increasing of I-squared value. Because few articles were available on some subgroups, Tau-squared is more suitable because it is not influenced by the number of studies. The results were expressed in geographic maps using Arc View 3.2 software (ESRI Inc., New York). For provinces with more than one study, the pooled estimation of anti-HDV prevalence was computed using the meta command, and then a survey-data analysis was used to estimate more accurate HDV-infection prevalence considering the weight of each city (17), which was calculated as the ratio of the city's HBV population to the study's sample size. The HBV population was calculated for each city by multiplying the city population (17) by 
the HBV-prevalence estimate (9). The same method was used to calculate HDV prevalence for both genders.

Subgroup analyses were designed according to disease patterns (cirrhotic, chronic hepatitis, and inactive carriers) and quality assessment scores (good and moderate). An overall meta-analysis was performed for each risk factor to determine whether the factor increased HDV prevalence. The available data were used to calculate or confirm the unadjusted odds ratio (OR). Risk factors, without complete data to calculate their OR, were omitted. To make pooled estimates, the authors used the "metan" command to compute point-estimation ORs with a 95\% CI for each risk factor. The analysis was performed with STATA 11 software (STATA Corp. LP).

\section{Results}

\subsection{Studies}

Ninety-six articles were found in the literature review, 40 of which $(4,10-13,15,18-49)$ were potentially related to HDV prevalence in Iran. The detailed search process is demonstrated in Diagram 1. Investigators sent an e-mail to the authors of four articles to obtain full text that was not available in the online databases $(24,44,46,48)$. Only two authors $(24,44)$ responded within one month. After filtering the studies based on the inclusion criteria explained above, 19 studies were identified as assessing the prevalence of HDV infection in Iran. Out of these, four studies were conducted in Tehran $(19,22,35,38)$, two studies in Shiraz and $(10,45)$ Hamedan $(21,23)$, and 1 each in the cities of Shahrekord (28), Mashhad (32), Khuzestan (33), Isfahan (24), Sari (11), Golestan (39), Babol (34), Bushehr (12), Kerman (49), and Tabriz (41). Additionally, one study was carried out in both Tehran and Tabriz (44) (Table 1). All of the studies in this report were based on crosssectional study designs conducted between 1983 and 2009 , and the sample sizes ranged from 16 to 1,725 . The ages of the study subjects ranged from 24 to 43 . All studies measured anti-HDV with individual patients' serums.

\subsection{HDV Infection Prevalence}

Reported HDV prevalence varied widely, from $0 \%$ in Sari (11) to $20 \%$ in Bushehr (12). Based on the heterogeneity tests $(\mathrm{Q}=20,967.40 \mathrm{df}=18, P<.001$; I-squared $=99.9 \%)$, a random model was considered. Furthermore, Tausquared indicated a variance of 18 between studies. The point estimation of HDV prevalence among 5,700 HBsAgpositive patients from 13 cities in Iran was 7.8\% (95\% CI: 5.89 - 9.71) from 1983 to 2009 . According to the survey-data analysis, the HDV prevalence for each city was weighted using the HBV prevalence of the province's population divided by the sample size (Table 1). The weighted mean prevalence of HDV infection calculated from 4,853 participants was 6.61\% (95\% CI: 6.59 - 6.63). The total population of the cities considered in this survey was about $44 \%$ of the total population of Iran.

\subsection{HDV Prevalence in Cirrhotic, Chronic-Hepatitis,}

\section{Inactive-Carrier Patients}

One source of heterogeneity was the different target populations in the studies. Therefore, the point estimations were broken into three subgroups: cirrhotic, chronic-hepatitis, and inactive-carrier patients. There were 198 patients in the cirrhotic and HCC groups ( 4 articles: $4,12,33,39)$, and the pooled estimation in this group was 30.47\% (95\% CI: 9.76 - 51.19). In chronic hepatitis group among 1,114 patients, the HDV prevalence in the random model was 14.4\% (95\% CI: 7.72 - 21.07; 7 articles: 19, 21, 33, $38,44,45,49)$.In 4,372 inactive carrier patients, the HDV prevalence was $4.94 \%$ (95\% CI: 3.73 - 6.15; 15 articles: $(10,11$, 19, 21-24, 28, 33-35, 38, 39, 41, 44) (Figure 1).

\subsection{HDV Prevalence According to Different Article Qual- ity}

The subgroup analyses depended on the quality of the studies. The HDV prevalence in articles $(21,23,24,33,45$, 48 ), which had good quality scores was $7.15 \%$ (95\% CI: 3.14 to 11.14). In papers with moderate quality scores, the HDV prevalence was $8.09 \%$ (95\% CI: $6.02-10.15)$. In low-quality studies, the HDV prevalence was 5.04\% (95\% CI: -4.65 14.75).

\subsection{Gender Subgroup Analysis}

The pooled estimations for women and men were calculated separately using a survey-data-analysis method. The prevalence of HDV was estimated at $8.63 \%$ (95\% CI: 8.53 - 8.73) among 2,644 men and 5.34\% (95\% CI: 5.26 - 5.44) among 1,390 women.

\subsection{Risk Factors}

Ten articles (19, 21, 22, 24, 34, 35, 38, 39, 41, 45) mentioned risk factors. Point estimations were calculated for factors such as history of blood transfusion, intravenous drug abuse, and hemodialysis and HBeAg positive serology. Table 2 demonstrates the relationship between different risk factors and anti-HDV serology.

\section{Conclusions}

According to our results, the overall estimation of HDV seropositivity in Iran is about $6.61 \%$ in HBsAg positive patients. The estimates were also run for asymptomatic and symptomatic HBsAg-positive patients. In our findings, the overall estimation in the asymptomatic group was about $5 \%$, and the time trend did not follow a recognizable pattern. Without considering outliers, the HDV prevalence moved closer to 5\%. The HDV prevalence among symptomatic HBsAg-positive patients was about $14.5 \%$, and it has been increasing over the years. The increase in HDV prevalence among symptomatic HBsAgpositive is different from the reports of declining cases in Italy (50), Spain (51), Taiwan (52), and Turkey (53). The declining incidence rates in these countries may be related to better detection. In addition, the HDV-infection rate in the Iranian population is lower in comparison with oth- 


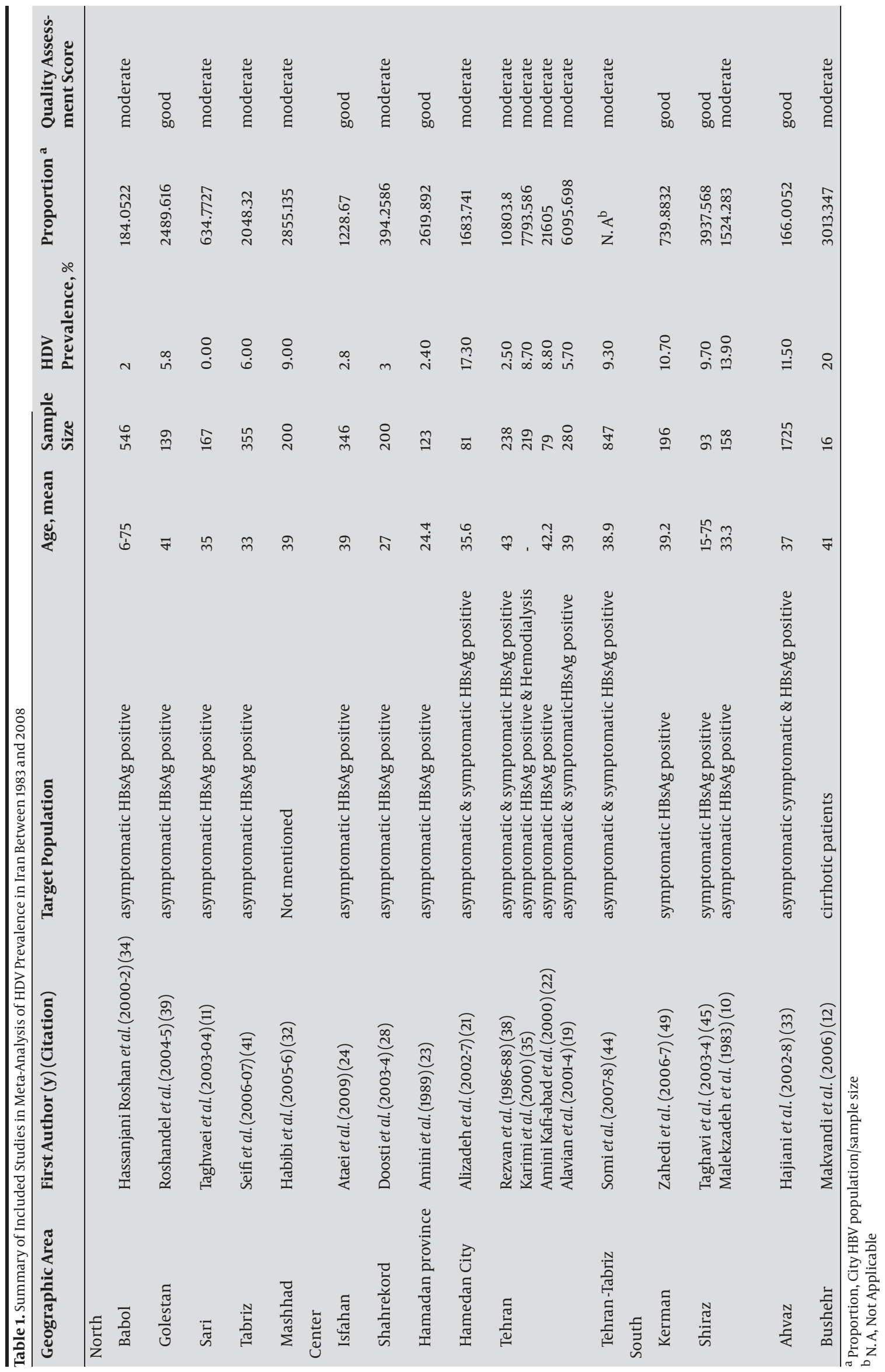




\begin{tabular}{|c|c|c|c|c|c|}
\hline & Study(Investigation Year) & OR & 95\% CI & Weighting Score & Pooled Estimation $(95 \% \mathrm{CI})$ \\
\hline \multirow[t]{4}{*}{ Blood transfusion } & & & & & $1.1(0.40-2.98)$ \\
\hline & Alizadeh et al.(2002-2007)(21) & 0.43 & $0.05-3.73$ & 0.84 & \\
\hline & Taghavi et al.(2003-2004)(45) & 0.62 & $0.07-5.4$ & 0.83 & \\
\hline & Alavian et al.(2001-2004)(19) & 2.4 & $0.64-9.1$ & 2.18 & \\
\hline \multirow[t]{6}{*}{ HBeAg positive } & & & & & $1.26(0.66-2.4)$ \\
\hline & Ataei et al.(2009)(24) & 0.72 & $0.15-3.4$ & 1.56 & \\
\hline & Alizadeh et al.(2002-2007) (21) & 2.2 & $0.66-7.22$ & 2.70 & \\
\hline & Hassanjani Roshan et al. (2000-2002) (34) & 5.1 & $1.47-18.33$ & 2.42 & \\
\hline & Rezvan et al.(1986-1988)(38) & 0.83 & $0.025-0.27$ & 2.67 & \\
\hline & Amini Kafi-abad et al.(2000)(22) & 0 & & & \\
\hline \multirow[t]{4}{*}{ IDU } & & & & & $1.6(0.78-3.214)$ \\
\hline & Taghavi et al.(2003-2004)(45) & 5.92 & $1.36-25.78$ & 1.77 & \\
\hline & Jedari Seifi et al.(2006-2007) (41) & 2.45 & $1-6.03$ & 4.75 & \\
\hline & Alizadeh et al.(2002-2007)(21) & 2.06 & $0.35-11.92$ & 1.25 & \\
\hline \multirow[t]{4}{*}{ Hemodialysis } & & & & & $1.72(0.79-3.76)$ \\
\hline & Karimi et al.(2000)(35) & 24.79 & $5.56-110.48$ & 1.72 & \\
\hline & Jedari Seifi et al.(2006-07) (41) & 1.7 & $0.68-4.23$ & 4.61 & \\
\hline & Taghavi et al.(2003-2004)(45) & 0 & & & \\
\hline
\end{tabular}

\begin{tabular}{|c|c|c|c|c|c|c|}
\hline & $\begin{array}{l}\text { Country/ } \\
\text { Region }\end{array}$ & $\begin{array}{l}\text { Target } \\
\text { Population }\end{array}$ & Prevalence, $\%$ & Sample Size & $\begin{array}{l}\text { Neighbors City } \\
\text { in Iran }\end{array}$ & $\begin{array}{l}\text { Prevalence in } \\
\text { Neighbors, } \%\end{array}$ \\
\hline $\begin{array}{l}\text { Degertekin H et al. } \\
(2008)(53)\end{array}$ & $\begin{array}{l}\text { Turkey/ } \\
\text { middle east }\end{array}$ & Meta-analysis & 27.1 & 6734 & Tabriz & 6 \\
\hline $\begin{array}{l}\text { Jacobson IM et al. } \\
(1985)(56)\end{array}$ & $\begin{array}{l}\text { Afghanistan/ } \\
\text { EMRO }\end{array}$ & $\begin{array}{l}\text { high risk group and } \\
\text { patients }\end{array}$ & 28.6 & 362 & Mashhad & 9 \\
\hline $\begin{array}{l}\text { Baig S et al. } \\
(2009)(57)\end{array}$ & $\begin{array}{l}\text { Pakistan/ } \\
\text { EMRO }\end{array}$ & patients & 37 & 129 & Kerman & 10.7 \\
\hline $\begin{array}{l}\text { Al Tarif I et al. } \\
(2004)(58)\end{array}$ & $\begin{array}{l}\text { Saudi Arabia/ } \\
\text { EMRO }\end{array}$ & patients & 8.6 & 19250 & Khuzestan & 11.5 \\
\hline $\begin{array}{l}\text { Zaki S et al. } \\
(2010)(59)\end{array}$ & $\begin{array}{l}\text { Egypt/ } \\
\text { EMRO }\end{array}$ & $\begin{array}{l}\text { high risk group and } \\
\text { patients }\end{array}$ & 20 & 100 & none & - \\
\hline $\begin{array}{l}\text { Gaeta GB et al. } \\
(2003)(50)\end{array}$ & $\begin{array}{l}\text { Italy/ } \\
\text { Europe }\end{array}$ & 14 referral liver unites & 8.3 & 834 & none & - \\
\hline $\begin{array}{l}\text { Chen X et al. } \\
(1998)(60)\end{array}$ & $\begin{array}{l}\text { China/ } \\
\text { Asia }\end{array}$ & $\begin{array}{l}\text { sample infected with } \\
\text { HBV }\end{array}$ & 7.72 & 2681 & none & - \\
\hline
\end{tabular}

er countries in the Eastern Mediterranean Region (7, 54), and it is nearer to the rates in European and East Asian countries (Table 3).

HDV is more common in the south of Iran than in the north. However, HBV prevalence is higher in the north (9). The difference in HDV rates may be due to factors that have an impact on HDV acquisition such as the generally lower socioeconomic status in south of Iran. Moreover, we have scarce data about HBV and HDV prevalence rates in southern Iran (Figure 2).

Our findings show that HDV is more common among cirrhotic and HCC patients. In a retrospective study in
European patients with HBV-related cirrhosis, Fattovich et al. (54) found that the risk of HCC increased 3 times in HDV patients. In another study, during 233 months of follow-up (3), $82 \%$ and $15 \%$ of chronic HDV patients developed cirrhosis and HCC. This finding indicates that HDV causes a severe form of chronic hepatitis in comparison with HBV monoinfection. The longer history and more severe condition cause a higher rate of anti-HDV antibody, which is in line with previous studies.

In our study, the prevalence of HDV was higher in males (8.63\%) than in females (5.34\%). Blood transfusion was generally more common in women, but we could not 


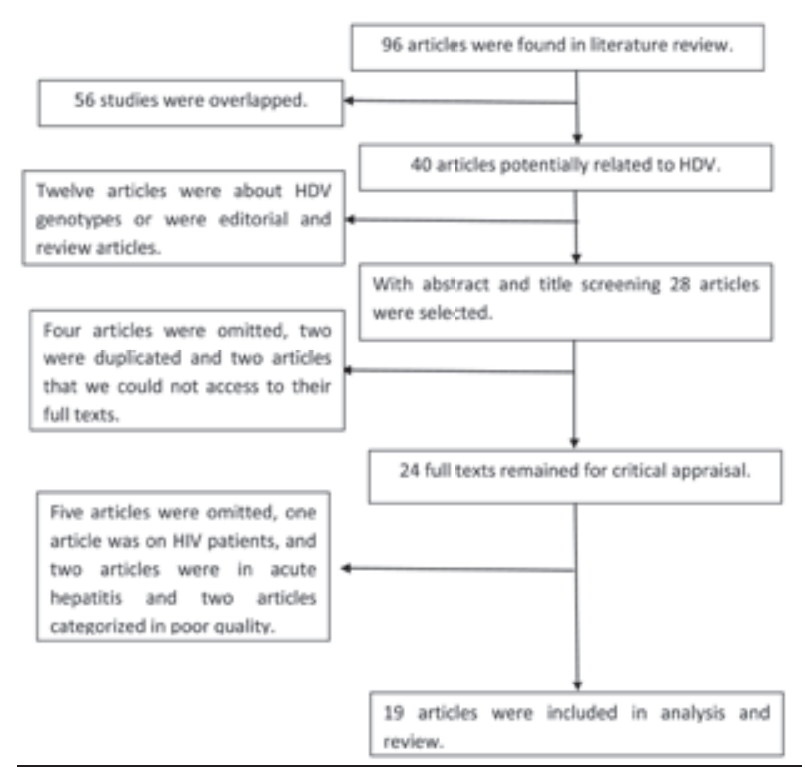

Diagram 1. Article Selection Process for HDV Infection in Iran up to December 2010

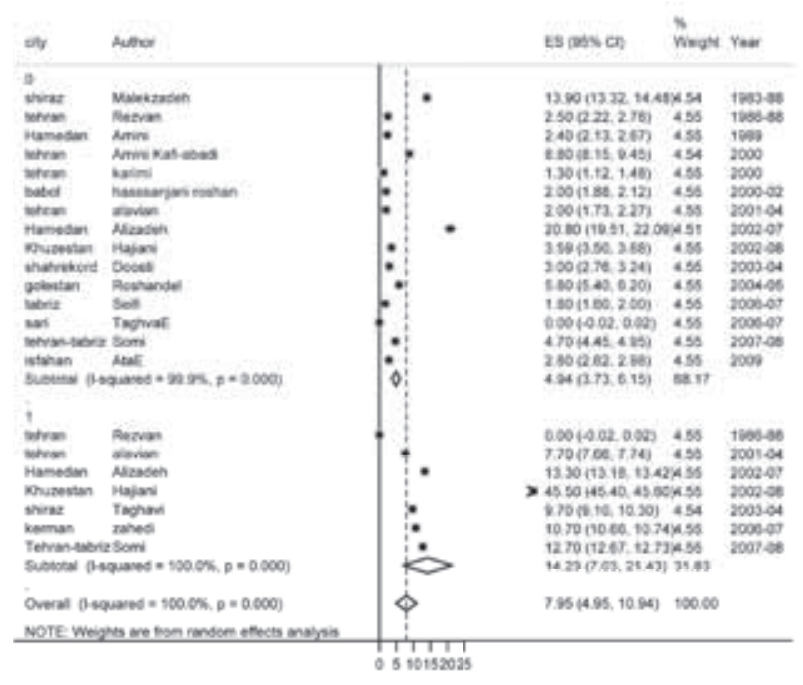

$\overline{\text { Figure 1. Forest Plot of HDV Infection Prevalence Among HBsAg-Positive }}$ Patients in Iran, 1983-2008

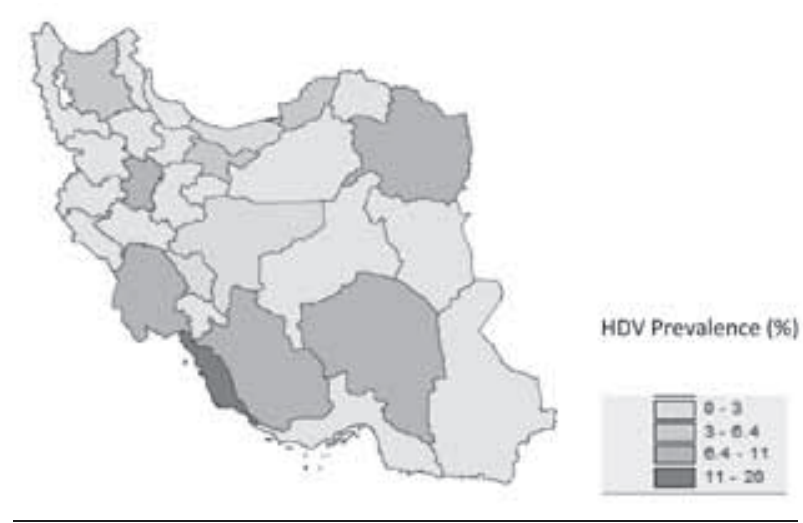

Figure 2. Regional Distribution of Pooled or Individual Prevalence of Hepatitis D Virus Infection Among HBsAg-Positive Patients in Iran, 19832008 detect this factor's impact on HDV prevalence. However, other factors, such as a greater possibility of multiple partners, intravenous drug abuse, war injury, and a higher rate of HBV infection in men (9), can be explained as possible causes of this divergence. The results of this study showed that the main routes of transmission for HDV are blood and blood products; therefore, individuals with a history of transfusion, surgery, tattooing, war injury, dentistry interventions, endoscopy, hemodialysis, intravenous drug use, and patients with coagulation factor disorder are at risk of HDV. This route of transmission is more similar to Western Europe and United states (55). The important groups in our review were hemodialysis patients and intravenous drug users. However, this association was not statistically significant, which may be due to the unadjusted ORs to others factors. We did not have enough data to assess interfamilial and sexually transmitted routes. In addition, the trend of the disease in HBeAg-positive patients with hepatitis D has not been well established. Previous articles showed HBeAg-positive rates of 15 to $30 \%$ among HDV patients (6). Our findings demonstrate that HDV is more common in patients who are HBeAg positive.

This review has some limitations, such as the lack of library and thesis searches. Additionally, data were available from $43 \%$ of provinces, and most of the data came from urban areas. The common method used for HDV detection was ELISA. Confirmation of ongoing HDV infection by PCR testing of HDV RNA was missing. The impact of this lack of information was that patients with and without active delta infection could be differentiated. The strongest part of this study was the use of a surveydata analysis in addition to the usual meta commands to generalize the results to the whole population. Moreover, a critical appraisal allows for more accurate estimates. A quality subgroup analysis showed that the low-quality papers underestimated HDV prevalence.

In conclusion, the prevalence of HDV is less common in Iran than in endemic regions; however, this is a severe form of hepatitis in Iranian patients. The most probable route of HDV transmission is hematologic, which shows the importance of blood screening for HDV, especially in groups with numerous blood transfusions. Information is lacking from some provinces, and ongoing research is required to understand the effects of HDV infection on HBsAg-positive patients and its risk factors. More research should be conducted on HDV to develop innovate strategies to control and diagnose this most severe form of viral hepatitis.

\section{Acknowledgments}

The authors thank Dr. Ali-Akbar Haghdoost from Kerman University of Medical Sciences for his valuable and professional help with the analysis of the results.

\section{Financial Disclosure}

None declared. 


\section{Funding/Support}

None declared.

\section{References}

1. Sagnelli E, Coppola N, Scolastico C, Filippini P, Santantonio T, Stroffolini T, et al. Virologic and clinical expressions of reciprocal inhibitory effect of hepatitis B, C, and delta viruses in patients with chronic hepatitis. Hepatology. 2000;32(5):1106-10.

2. Fattovich G, Boscaro S, Noventa F, Pornaro E, Stenico D, Alberti A et al. Influence of hepatitis delta virus infection on progression to cirrhosis in chronic hepatitis type B.J Infect Dis.1987;155(5):931-

3. Romeo R, Del Ninno E, Rumi M, Russo A, Sangiovanni A, de Franchis R, et al. A 28-year study of the course of hepatitis Delta infection: a risk factor for cirrhosis and hepatocellular carcinoma. Gastroenterology. 2009;136(5):1629-38.

4. Alavian SM, Alavian SH. Hepatitis D Virus Infection; Iran, Middle East and Central Asia. Hepat Mon. 2005;5(4):137-43.

5. Farci P. Delta hepatitis: an update. J Hepatol. 2003;39(Supp 1):S212-9.

6. Heidrich B, Deterding K, Tillmann HL, Raupach R, Manns MP, Wedemeyer H. Virol and clinical characteristics of delta hepat in Central Europe. J Viral Hepat. 2009;16(12):883-94.

7. Khan A, Kurbanov F, Tanaka Y, Elkady A, Sugiyama M, Dustov A, et al. Epidemiological and clinical evaluation of hepatitis B, hepatitis C, and delta hepatitis viruses in Tajikistan. J Med Virol. 2008;80(2):268-76.

8. Flodgren E, Bengtsson S, Knutsson M, Strebkova EA, Kidd AH, Alexeyev OA, et al. Recent high incidence of fulminant hepatitis in Samara, Russia: molecular analysis of prevailing hepatitis B and D virus strains. JClin Microbiol. 2000;38(9):3311-6.

9. Alavian SM, Kabir A, Ahmadi AB, Lankarani KB, Shahbabaie MA, Ahmadzad-Asl M. Hepatitis C infection in hemodialysis patients in Iran: a systematic review. Hemodial Int. 2010;14(3):253-62.

10. Malekzadeh R, Borhanmanesh F. Prevalence of HDV in as ymptomatic healthy carrier of HBV in Iran. Iran J Med Sci. 1989;14(2):33-8.

11. Taghvaei T, Khanlarpor M, Mahdavi Mohammad R, Tirgar Fakher H, Maleki I, Khalilian A. Prevalence of positive Hepatitis Delta Virus in patients with positive Hepatitis B surface Antigen and its correlative factors in Sari. J Mazandaran Univ Med Sci. 2009;18(67):102-6.

12. Makvandi M, Aryan E. Study on hepatitis B and D markers among the patient in buchehr city. Bio and Cellular Arch. 2010;10(1):103-5.

13. Salahei M, Ansari Moghaddam A, Sanei Moghaddam E, Khosravi S, Hajibeigi B, Alavian S. The epidemiological pattern of acute viral hepatitis in Tehran and Zahedan: A comparison study. Gastroenterol Hepatol Bed Bench. 2009;3(1).

14. Salehi M, Sanei ME, Khosravi S. Etiology of acute viral Hepatitis in Zahedan. J Shahid Beheshti Univ Med Sci. 2003;4(26):245-8.

15. Salehi M, Sharifi B. Acute viral hepatitis in Zahedan: A serological analyzes of 263 case. J Med Sci (Pakistan). 2005;5(2):101-5.

16. Glynn L. EBLIP Critical Appraisal Checklist. Memorial University of Newfoundland. [updated; Available from: http://www.nihs.ie/ pdf/EBL\%20Critical\%20Appraisal\%20Checklist.pdf.

17. Statistical Center of Iran. [updated 2010]; Available from: http:/| www.amar.org.ir/Default.aspx.

18. Abbas Z, Jafri W, Raza S. Hepatitis D: Scenario in the Asia-Pacific region. World J Gastroenterol. 2010;16(5):554-62.

19. Alavian SM, Asari SH, Manzoori-Joybari H, Moghani Lankarani M, Doroudi T, HajiBeigi B, et al. [Frequency and risk factors of hepatitis D virus in hepatitis B patients]. Govaresh. 2004;3(9):169-75.

20. Alavian SM. We have more data regarding epidemiology of hepatitis D in Iran but there are defects to be filled yet. Hepat Mon. 2008;8(4):245-7.

21. Alizadeh AH, Ranjbar M, Tehrani AS, Keramat F, Mamani M, Rezazadeh $\mathrm{M}$, et al. Seroprevalence of hepatitis D virus and its risk factors in the west of Iran.J Microbiol Immunol Infect. 2010;43(6):51923.

22. Amini S, Taghinia A, Khanbaba F, Talebian A. [Prevalence of Delta agent super-infection and co-infection among HBsAgpositive patients referring to reference IBTO Lab]. Hakim Res J.
2007;9(4):7-11.

23. Amini S, Mahmoodi MF, Andalibi S, Solati A. Seroepidemiology of hepatitis B, delta and human immunodeficiency virus infections in Hamadan province, Iran: a population based study. J Trop Med Hyg. 1993;96(5):277-87.

24. Ataei B, Kalantari H, Soleimani S, Javadi A, Adibi P, Yaran M, et al. Delta hepatitis infection in patients with chronic hepatitis $B$ infection in Isfahan, Iran: P2003. Clin Microbiol Infect. 2009;15(4 Suppl 1):S586.

25. Bashardust N. seroprevalance of HDV in high risk group. Med $J$ shahid sadughi yazd. 1999;3:51.

26. Behzadian F, Sabahi F, Karimi M, Sadeghizadeh M, Maghsoudi N, Forooshani RS, et al. Molecular phylogenetic analysis of Iranian HDV complete genome. Virus Genes. 2005;30(3):383-93.

27. Behzadian F, Sabahi F, Sadeghizadeh M, Maghsoudi N, Fotouhi F, Karimi M. In vitro replication of hepatitis D virus using a new construct containing a cDNA dimer of HDV genome. Intervirology. 2007;50(6):387-93.

28. Doosti A, Amini-Bavil-Olyaee S, Tajbakhsh E, Adeli A, Mahboudi F. Prevalence of viral hepatitis and molecular analysis of HBV among voluntary blood donors in west Iran. New Microbiol. 2009;32(2):193-8.

29. Esmaeili R, Alavian SM, Hajibeigi B, Sabouri E, Edalat R, Adeli A, et al. Phylogenetic analysis of twenty-six cases of hepatitis delta virus isolates in Tehran, Iran. Hepat Mon. 2009;9(3):196-200.

30. Fallahian F, Alavian SM, Fallahian V, Zamani F. Impact of immunosuppression and chemotherapy on reactivation of viral hepatitis. Saudi J Kidney Dis Transpl. 2010;21(4):621-7.

31. Gholamreza R, Shahryar S, Abbasali K, Hamidreza J, Abdolvahab M, Khodaberdi K, et al. Seroprevalence of hepatitis B virus and its co-infection with hepatitis D virus and hepatitis $C$ virus in Iranian adult population. Indian J Med Sci. 2007;61(5):263-8.

32. Habibi F, Mokhtari H, Gazerani M, Roshani Zaferanloo N. The Frequency of Hepatitis Delta in Hepatitis B surfuce antigen positive patients. Med Sci J Islamic Azad Univ-Mashhad Branch. 2000;5(3):61-7.

33. Hajiani E, Hashemi SJ, Jalali F. Seroprevalence of Delta Hepatitis in Patients with Chronic Hepatitis B and its Clinical Impact in Khuzestan Province, Southwest Iran. Hepat Mon. 2009;9(4):28792.

34. Hassanjani Roshan MR, Beigi AA, Soleimani MJ. [Prevalence of anti-HDV in chronic carrier of HBV in Babol]. Babol Med J. 2004;6(21):50-4.

35. Karimi A, Amini S, Amirkhani A. [Investigation and Comparison of hepatitis D prevalence in dialysis patients and the donors of HBsAg carrier]. teb va tazkieh. 2000(36):30-5.

36. Mirshafiee $H$, Mahmoodian-Shooshtari M, Sharifi Z, Hosseini SM. Genotype Analysis of Hepatitis Delta Virus from Hepatitis B Surface Antigen-Positive Patients Using PCR-RFLP in Tehran, Iran. Arch Iran Med. 2009;12(3):238-43.

37. Mohebbi SR, Zali N, Derakhshan F, Tahami A, Mashayekhi R, Amini-Bavil-Olyaee S, et al. Molecular epidemiology of hepatitis delta virus (HDV) in Iran: A preliminary report. J Med Virol. 2008;80(12):2092-9.

38. Rezvan H, Taroyan S, Forouzandeh B, Fadaiee S, Azordegan F. A study on delta virus infection and its clinical impact in Iran. In fection. 1990;18(1):26-8.

39. Roshandel G, Semnani S, Abdolahi N, Besharat S, Keshtkar AA Joshaqani $\mathrm{H}$, et al. Prevalence of hepatitis D virus infection in hepatitis B surface antigen-positive subjects in Golestan province, northeast Iran. J Microbiol Immunol Infect. 2008;41(3):227-30.

40. Roshandel G, Semnani S, Abdolahi N, Keshtkar AA, Besharat S, Joshaghani $\mathrm{H}$, et al. Prevalence of hepatitis D virus infection in HBsAg positive subjects in Iran. PakJ Biol Sci. 2007;10(10):1751-4.

41. Jedary Seifi S, Sabouri Ghannad M. A Study of HDV in HBsAg Positive Patients in Tabriz, Northwestern Iran. Hepat Mon. 2010;10(2):110-5.

42. Shahinsaz L, Sabahi F, Karimi M, Behzadian F, Alavian S, Zand V. Detection and genotyping of hepatitis D virus from HBsAg positive patients in Iran using RT-PCR. Iran J Biotech. 2006;4(3):174-9.

43. Vaziri S, Mansouri F, Sayad B, Afsharian M, Janbakhsh A, Karami M. Hepatitis D Virus Infection among HIV-HBV Co-Infected Patients in Kermanshah, West of Iran. Hepat Mon. 2008;8(4):252-7.

44. Somi MH, Farhang S, Miri SM, Pouri AA, Mjidi G, Alavian SM. The 
frequency of hepatitis D virus in patients with hepatitis B in Iran: an increasing rate? Trop Doct. 2009;39(3):154-6.

45. Taghavi SA, Sedighi SH, Mehrabani D, Khademolhosseini F. Hepatitis D in chronic active hepatitis B: prevalence, liver enzymes and histopathology- an epidemiological study in Shiraz, southern Iran, 2003-2004. Hepat Mon. 2008;8(4):248-51.

46. Torabi SE, Ebrahimpoor S, Maljaei SH, Naghili B. Seroepidemiological studies of Hepatitis Delta (HDV) in HBsAg positive individuals in Tabriz. J urmia univ Med Sci. 2003;13(4):290-7.

47. Vosoughinia H, Esmailzadeh A, Mokhtarifard A, Sima HR, Saadatnia H, Khosravi A. Seroepidemiology and co infetion of hepatitis D virus infection in the north-east of Iran. Med J Mashhad Univ Med Sci. 2010;53(2):69-72.

48. Zahedi MJ. Serologic Prevalence of Hepatitis D in HBsAg Positive Patients in Kerman, South of Iran. Kerman Univ Med Sci and Health Serv. 2003.

49. Zahedi MI, Darvish-Moghaddam S, Zareei H. Clinical Impact and Frequency of Hepatitis D Virus Infection in HBsAg Positive Patients in a Southern Province of Iran (Kerman). Iran J Virol. 2010;3(2):1-6.

50. Gaeta GB, Stroffolini T, Chiaramonte M, Ascione T, Stornaiuolo G, Lobello S, et al. Chronic hepatitis D: a vanishing Disease? An Italian multicenter study. Hepatology. 2000;32(4 Pt 1):824-7.

51. Navascues CA, Rodriguez M, Sotorrio NG, Sala P, Linares A, Suarez A, et al. Epidemiology of hepatitis D virus infection: changes in the last 14 years. Am J Gastroenterol. 1995;90(11):1981-4.

52. Huo TI, Wu JC, Lin RY, Sheng WY, Chang FY, Lee SD. Decreasing hepatitis D virus infection in Taiwan: an analysis of contributory factors. J Gastroenterol Hepatol. 1997;12(11):747-51.

53. Degertekin H, Yalcin K, Yakut M, Yurdaydin C. Seropositivity for delta hepatitis in patients with chronic hepatitis B and liver cirrhosis in Turkey: a meta-analysis. Liver Int. 2008;28(4):494-8.

54. Fattovich G, Giustina G, Christensen E, Pantalena M, Zagni I, Realdi G, et al. Influence of hepatitis delta virus infection on morbidity and mortality in compensated cirrhosis type B. The European Concerted Action on Viral Hepatitis (Eurohep). Gut. 2000;46(3):420-6.

55. Pascarella S, Negro F. Hepatitis D virus: an update. Liver Int. 2011;31(1):7-21.

56. Jacobson IM, Dienstag JL, Werner BG, Brettler DB, Levine PH, Mushahwar IK. Epidemiology and clinical impact of hepatitis D virus (delta) infection. Hepatology. [10.1002/hep.1840050205]. 1985;5(2):188-91.

57. Baig S, Siddiqui AA, Ahmed WU, Qureshi H, Arif A. Frequency of hepatitis C and D super infection in patients with hepatitis B related complex liver disorders. J Coll Physicians Surg Pak. 2009;19(11):699-703.

58. Al Traif I, Ali A, Dafalla M, Al Tamimi W, Qassem L. Prevalence of hepatitis delta antibody among HBsAg carriers in Saudi Arabia. Ann Saudi Med. 2004;24(5):343-4.

59. Zaki S, Abou Khatwa M, Mikhail H. PP-100 Prevalence of infection with delta virus in patients positive for hepatitis B surface antigen. Int J Infect Dis. 2010;14(Suppl 2):S55.

60. Chen X, Xuan M, Yin Y. [Study of HDV infection in Shandong province]. Zhonghua Liu Xing Bing Xue Za Zhi. 1998;19(3):138-40. 